\title{
Desarrollo moral en los estudiantes mexicanos: Un análisis de la visión de justicia de la teoría de Kohlberg
}

\section{Moral development in Mexican students: Analisis of the Kohlberg's theory vision of justice}

DOI: https://doi.org/10.17981/juridcuc.15.1.2019.03

\author{
María Glafira Sandoval Benavides (iD \\ Universidad Autónoma de Zacatecas (México) \\ glafiris@hotmail.com \\ María Teresa Villegas Santillán \\ Universidad Autónoma de Zacatecas (México) \\ cpmtvs@hotmail.com \\ Reina Margarita Vega Esparza \\ Universidad Autónoma de Zacatecas (México) \\ reinavega_62@yahoo.com.mx
}

Para citar este artículo:

Sandoval, M., M. Villegas y Vega, R. (2019). Desarrollo moral en los estudiantes mexicanos: Un análisis de la visión de justicia de la teoría de kohlberg. JURÍDICAS CUC, 15(1). 69-95. DOI: http://dx.doi.org/10.17981/juridcuc.15.1.2019.03

\section{Resumen}

La educación implica cambios profundos generadores de procesos inacabables de construcción del sujeto. Actualmente, la educación recurre a la capacitación para la productividad y la competitividad, mediante un conocimiento memorístico, mecánico y utilitarista. La tarea del Siglo XXI para los ciudadanos es asumir su responsabilidad cívica. El objetivo de la investigación era determinar el desarrollo moral de un grupo de estudiantes mexicanos de acuerdo a la teoría y metodología de Kohlberg. A partir de entrevistas focalizadas se obtuvieron resultados con niveles preconvencionales, donde prevalece el respeto a las leyes, sin importar el bien común, hasta niveles convencionales, en los cuales se respetan las leyes, la justicia y el bienestar general. Con el fin de mejorar esta visión moral y de justicia, precursora del bien común se proponen estrategias educativas para los estudiantes.

Palabras Clave: Alumnos; Desarrollo moral; Justicia; Teoría de Kohlberg.

\begin{abstract}
Education implies profound changes that generate endless processes of construction of the subject. Currently, education resorts to training for productivity and competitiveness, through memoristic, mechanical and utilitarian knowledge. The task of the 21st century for citizens is to assume their civic responsibility. The objective of the research was to determine the moral development of a group of Mexican students according to Kohlberg's theory and methodology. From focused interviews, results were obtained at pre-conventional levels, where respect for the law prevails, regardless of the common good, up to conventional levels, in which laws, justice and general welfare are respected. In order to improve this moral and justice vision, precursor of the common good, educational strategies for students are proposed.
\end{abstract}

Keywords: Students; Moral development; Justice; Kohlberg theory. 


\section{Introducción}

Existe la necesidad de forjar en los ciudadanos la civilidad, asimismo, se requiere una sociedad civil que asuma su responsabilidad como parte de un todo. Nos encontramos en una sociedad con desigualdades económicas, las cuales junto con el capitalismo han sido el generador de ver al individuo deshumanizado, donde la ética del individualismo hedonista es lo que impera.

En la vida hedonista se produce una pérdida de la voluntad y la fortaleza. Más importante aún es que los hombres se hacen competitivos en la prosecución de los lujos, y pierden la capacidad de compartir y sacrificarse [...] A esto sigue la pérdida de la solidaridad que hace a los hombres sentirse hermanos unos de otros, ese sentimiento de grupos que supone efecto mutuo y la disposición a combatir y luchar unos por otros (Bell, 2006, p. 25).

Cuando el hedonismo es la clave de una sociedad se acaba con la capacidad de civilidad, es decir, la capacidad de sacrificarse e involucrarse de manera activa en las tareas públicas y de sociedad en general. Pero este comportamiento hedonista se ha convertido como señala Mac Pherson (2005) en "el único criterio defendible racionalmente del bien social era la mayor felicidad del mayor número, en el cual se definiría la felicidad como la cantidad de placer individual una vez restado el dolor" (p. 37). Este es uno de los conceptos de la democracia capitalista, donde el ser humano es dueño de lo que produce y por lo tanto no le debe nada a la sociedad de su tener o haber.

Las filosofías imperante en las universidades de los años 70 fueron tomadas de las teorías del contrato, como la teoría de Hobbes, la de Kant o la de Rousseau. Estas teorías se volvieron conductoras de intereses egoístas de los ciudadanos, Filosofías de la vida que empiezan a entrar en crisis en los años 80 , donde el filósofo Alasdair Chalmers Maclntyre critica la cantidad desmedida de la teoría de la justicia la cual estaba centrada en un exceso de dimensión racional y había olvidado el marco 
sentimental, donde el concepto de pertenencia es fundamental. En este sentido, la autora Cortina (2003) señala como

... en los años 90, se volvió a poner de moda en el tapete de la reflexión la noción de ciudadanía. Y la noción de ciudadanía pretende ser una síntesis de justicia y de pertenencia. En último término, ¿quién es un ciudadano? Un ciudadano es alguien que se sabe perteneciente a una comunidad política, que sabe que está inscrito en su comunidad política [...] que quiere que esa comunidad sea justa (p. 3).

Sin embargo, los ciudadanos deben asumir la importancia que tiene el tejer redes sociales, siendo estas el principal capital de los pueblos. Para poder llegar a este tipo de ciudadanos, han sido señalados por Cortina (2003) cinco valores, tales como la libertad, la igualdad, la solidaridad, el respecto activo, y el diálogo como parte de la ética cívica. Al respecto, Cortina también señala que

... la ética cívica es la ética que puede compartir todos los ciudadanos de una comunidad pluralista. Estos valores están presentes en todas las éticas de máximos, todos los componentes y creo que son los que componen el bagaje que tiene que llevar en la mochila todo buen ciudadano (Cortina, 2003, p. 11).

Es importante, señalar como virtud del ser humano a la tolerancia, pero ésta debe ser entendida como el valor para diferenciar entre la impotencia e indiferencia y el respeto activo. Cuando un individuo es indiferente a lo que acontece a su alrededor es dañino a la sociedad. Por esto, para lograr la solidaridad en una sociedad es necesario inmiscuirse en los problemas comunes, generando así el respeto activo (Cortina, 2003).

El reto para este siglo XXI es para tanto hombres como mujeres asumir su protagonismo en materia de civilidad. En la actualidad, la humanidad está inmersa en el individualismo posesivo, el cual la ha llevado a una crisis social con una civilidad enferma. Tal es el caso de México, donde su sistema educativo está permeado por concepciones filosóficas o antropológicas, donde la enseñanza de la ética y valores es deficiente. 


\section{Fundamentos Teóricos}

\section{Historia de la axiología}

La historia señala como desde la antigua Grecia, los valores humanos han sido un tema de interés, y ha dejado diferencias entre los conceptos y las apreciaciones de los mismos. La rama de la filosofía encargada de estudiar los valores humanos se conoce como ética. Sócrates, afirmó "la virtud no es otra cosa que el saber, y si el saber se aprende se puede enseñar" (Sánchez, 2000, p. 72). Para Platón, las principales virtudes eran la fortaleza, la templanza, sabiduría y justicia (Platón, 1981). Aristóteles, discípulo de Platón, señalaba que

... la virtud se relaciona no tanto con el saber (proceso cognitivointelectual), sino con una disposición duradera del alma [...] afirma que el bien supremo o fin último es la felicidad, la cual se encuentra relacionada estrechamente con el desarrollo de las virtudes (Sánchez, 2000, p. 72).

En la filosofía cristiana-medieval prevaleció el pensamiento de San Agustín sobre los valores. San Agustín adoptó las ideas de Platón planteando al hombre como un ser poseedor de principios morales por naturaleza. Sin embargo, en el Renacimiento se cambió la forma de educar, y se señalaba que los principios morales no vienen con el ser humano por naturaleza, sino que se adquieren según la sociedad y la época.

En la época moderna, Rousseau afirmó que lo que afecta la moral al ser humano es el desarrollo de la sociedad. En el mismo periodo se cuenta con la presencia de Kant; para este filósofo el ser humano, y sus acciones, están determinadas por la razón, influenciada a su vez por el amor, el odio y la avaricia, entre otros. Todos estos elementos influyen en la buena voluntad del individuo, como lo exponen los planteamientos de Kant (1788/1961), quien es citado por Zerpa (2007), y se enuncian a continuación: 
En su crítica de la razón práctica, genera una serie de postulados que intentaban explicar la razón que determina la acción de las personas. Para Kant, lo importante era la autonomía del sujeto. Afirmaba que la consciencia moral es el reino de lo que debe ser, como una forma de oposición a la naturaleza, en tanto esta se constituye en el reino del ser. Al respecto, distinguía entre leyes naturales, por las cuales todo sucede y leyes de la libertad, según los cuales todo debe suceder. La ciencia de las primeras se llama Física; la de la segunda ética (Zerpa, 2007, p. 139).

Por consiguiente, sobre las bases expuestas por Kant (2003) se hace una reflexión sobre los principios de la razón pura y se describen de la siguiente manera:

Proporciones que contienen una determinación universal de la voluntad que tiene bajo sí varias reglas prácticas. Son subjetivas o máximas cuando la condición es considerada por el sujeto como calidad solamente para su voluntad, objetos o leyes prácticas, cuando la condición se reconoce como objetos, estos, es válida para la voluntad de todo ser racional (Kant, 2003, p. 16).

Es por ello, como de acuerdo a los planteamientos por el autor antes mencionado, el querer coincide con el deber, pero entra en conflicto porque la moral del ser humano lo condiciona a comportarse de acuerdo a las leyes de una sociedad, aunque sus deseos sean otros. Así, el ser humano considerado bueno es aquel que sojuzga sus propias reglas a partir del curso de la razón (Kant, 2003).

En el siglo XIX se desarrollaron otras corrientes filosóficas conocidas como el pragmatismo. Charles Sanders Pierce, William James y John Dewey son considerados los autores de esta corriente. El marxismo, ha sido otra corriente filosófica y sus principales autores fueron Carlos Marx y Federico Engels; esta corriente filosófica se promulgó por principios y valores como "la solidaridad, la fraternidad, la justicia social, la superación de la alineación económica, política y religiosa, el humanismo, el amor al trabajo, la aversión a una actitud parasitaria o aburguesada, etc.” (Sánchez, 2000, p. 74). 
Siguiendo con la historia y los cambios que han existido, con respecto a la moralidad, valores y ética, Hegel apuntaba a la moralidad como el paso previo a la eticidad. Hegel "subsumió la moral dentro del sistema y no le concedió ninguna autonomía, como también es cierto que redujo el contenido de la teoría ética a la propia realidad de las instituciones del espíritu objetivo" (Valcárcel, 1988, p. 18).

México es un país en desarrollo, eso implica crecimientotransición en todos los ámbitos y niveles. Hegel señalaba que para una sociedad cambiar o bien trasformarse, es importante adentrarse en su estructura social, política y económica, para estar conscientes del tipo de desarrollo al cual esta encaminada, y si como tal nos conduce a una mejor nación, y como consecuencia a una sociedad más humana.

\section{Desarrollo moral en las universidades según la teoría de Kohlberg}

Kohlberg asumió los postulados del enfoque teórico de Piaget y Kant en cuanto al juicio moral. En donde existen dos ideas fundamentales en la moralidad humana "la primera es la idea de que el desarrollo es socialización, es decir, el aprendizaje o internalización por parte del niño o del adolescente de las normas de la familia de la cultura" (Kohlberg, 2008, p. 43). En lo concerniente, este manifiesto conlleva a formular la teoría siguiente:

Teoría del aprendizaje social, que equipara la socialización moral con el aprendizaje en situaciones a través de medios y de esfuerzo. La teoría psicoanalítica, que apoya la temprana formación de un superego que induce a la culpa o a una conciencia a través de la identificación con o incorporación de, la autoridad de los padres y estándares. Las dos teorías están de acuerdo en que el desarrollo moral, es la internalización de los modelos de los padres y de las culturas (Kohlberg, 2008, p. 44). 
En el mismo hilo conductual de la presente disquisición, la teoría del desarrollo moral de Kohlberg, también conocida como la teoría de la moralización del desarrollo cognitivo, tiene la etiqueta cognitivo-evolutiva, y el punto central de la postura cognitivo-evolucionista es la teoría de estudios cognitivos. La cual, como lo señalan los autores Hersh, Reimer y Paolito (2002) posee las siguientes características:

Se desarrollan a partir de reflejos innatos, se organizan durante la infancia en esquemas de conducta, se internalizan durante el segundo año de vida como modelos de pensamiento, y se desarrollan durante la infancia y la adolescencia en las complejas estructuras intelectuales que caracterizan la vida adulta" (Hersh, Reimer y Paolito, 2002, p. 31).

De tal manera, los estadios cognitivos son integraciones jerárquicas y forman orden de estructuras crecientemente diferenciadas e integradas para completar una función común. Para Kohlberg (2008), los estadios estructurales se basan en una jerarquía de diferenciación e integración, y señala lo siguiente:

Cada conjunto teórico de estadios estructurales se define de tal manera, que un estadio superior es más diferenciado e integrado que un estadio inferior. En este sentido, un conjunto de estadios estructurales forma una jerarquía válida independientemente de si definen o no secuencias ontogenéticas (Kohlberg, 2008, p. 56).

Tal es el caso de los instintos básicos, donde ni la intervención temprana de los padres, ni la cantidad de diversos tipos de disciplina, se correlacionan con las actitudes o conductas morales según los estudios realizados por Kohlberg. Acerca del juicio moral, considerado por Kohlberg como "un proceso cognitivo que nos permite reflexionar sobre nuestros propios valores y ordenarlos en una jerarquía lógica" (Palomo, 1989, p. 5), éste nace y se desarrolla en todas las interacciones sociales.

En este mismo contexto, ha sido señalado que el sentido moral se desarrollan en dos etapas, el realismo moral y relativismo moral (Craig y Baucum, 2009, p. 316). 
En el relativismo moral las reglas se obedecen por ser reales e indestructibles, mientras en el realismo moral las reglas son creadas y aceptadas en forma cooperativa por los individuos. Sin embargo, para Piaget y Kohlberg la conciencia de reciprocidad lógica y la reciprocidad moral aparecen entre los seis y siete años de edad, dándose una forma cognitiva en el juicio moral (Kohlberg, 2008).

Kohlberg (2008) define los estadios de juicio moral tomando en cuenta otros estudios al respecto como los de Piaget, Baldwin, Perck Havighurts y McDougall. Para Kohlberg existen conceptos morales básicos y se aplican en cualquier sociedad, como son el valor, la elección de sanciones, los motivos, las reglas, los derechos, las autoridades, la justicia positiva y la justicia punitiva, cada una de ellas con su descripción y aspectos que las soportan.

Por otro lado, ha sido señalado que en el enfoque cognitivo de Kohlberg la moralidad resulta de principios morales universales, aunados a procesos inconscientes y aprendizajes tempranos (Barra, 1987, p. 4).

En opinión de Kohlberg (2008), muchas personas piensan sobre el juicio moral en términos de los valores adquiridos en su entorno social. Por lo tanto, una persona actúa, y debe actuar, de acuerdo con esos valores; esto es un pensamiento de sentido común que abarca a todo individuo en su vida diaria, no solo cuando considera lo que ocurre a su alrededor sino cuando los valores de una persona entran en conflicto.

La teoría de Kohlberg respecto al desarrollo y la educación moral nace, y depende del diseño de los estadios del juicio moral. Los seis estadios del juicio moral están divididos en tres niveles de razonamiento moral: nivel l preconvencional, nivel ll convencional y nivel III pos-convencional. "Para determinar el estadio del desarrollo moral de una persona, utiliza los dilemas hipotéticos (método clínico derivado) que, según el mismo autor, ayuda a ver las etapas más reales" (Palomo, 1989, p. 6). En la siguiente tabla se describen los niveles morales y sus características de acuerdo a Kohlberg (2008, p. 80). 
TABLA 1

Niveles morales y sus características

\begin{tabular}{|c|c|c|}
\hline Niveles & Base de juicio moral & Estadios de desarrollo \\
\hline I & $\begin{array}{l}\text { El valor moral reside } \\
\text { acontecimientos en } \\
\text { los malos actos o en } \\
\text { necesidades causas } \\
\text { físicas más que en } \\
\text { las personas y los } \\
\text { estándares. }\end{array}$ & $\begin{array}{l}\text { Estadio 1: orientación al castigo y } \\
\text { obediencia. Referencia egocéntrica } \\
\text { al poder o prestigio superiores, o una } \\
\text { tendencia a evitar problemas. } \\
\text { Estadio 2: orientación ingenuamente } \\
\text { egoísta. La acción concreta es la que } \\
\text { satisface las necesidades de uno y } \\
\text { ocasionalmente las de otro. Conciencia } \\
\text { del relativo valor de la perspectiva y } \\
\text { necesidades de cada actor. Orientación } \\
\text { al intercambio y la reciprocidad. }\end{array}$ \\
\hline II & $\begin{array}{l}\text { El valor moral reside } \\
\text { en interpretar roles } \\
\text { buenos o correctos, } \\
\text { en mantener el orden } \\
\text { las expectativas de los } \\
\text { demás. }\end{array}$ & $\begin{array}{l}\text { Estadio 3: orientación del buen chico } \\
\text { Orientación a agradar y aprobar a los } \\
\text { demás, así como ayudar. Conformidad a } \\
\text { imágenes estereotipadas de los mayores } \\
\text { y juicios por intenciones. } \\
\text { Estadio 4: orientación de mantenimiento } \\
\text { de la autoridad y orden social. Orientación } \\
\text { a "cumplir él deber y a mostrar respeto } \\
\text { por la autoridad y mantener el orden } \\
\text { social dado por sí mismo. }\end{array}$ \\
\hline III & $\begin{array}{l}\text { El valor moral reside } \\
\text { en la conformidad del } \\
\text { ego con estándares, } \\
\text { derechos o deberes } \\
\text { compartidos o } \\
\text { compartibles. }\end{array}$ & $\begin{array}{l}\text { Estadio 5: orientación legalista } \\
\text { contractual. Reconocimiento de un } \\
\text { elemento arbitrario o punto de partida } \\
\text { en reglas o expectativas para llegar a un } \\
\text { acuerdo. El deber se define en términos } \\
\text { de contrato, evitando a la violación de los } \\
\text { derechos de otros y según la voluntad y } \\
\text { bienestar de la mayoría. } \\
\text { Estadio 6: Orientación de conciencia o } \\
\text { principio. Orientación no sólo hacia reglas } \\
\text { sociales ordenadas sino a principios } \\
\text { de elección que requieren la llamada a } \\
\text { una consistencia y universalidad lógica. } \\
\text { Orientación a la conciencia como un } \\
\text { agente dirigente y a un mutuo respeto } \\
\text { y confianza. }\end{array}$ \\
\hline
\end{tabular}

Fuente: Elaboración propia a partir de Kohlberg (2008, p. 80). 
Para Kohlberg, las personas del nivel preconvencional no están interesadas en lo que la sociedad ha determinado correcto en una situación dada, sino sólo en las consecuencias concretas con las que se enfrentan los individuos. Una persona de este nivel convencional enfoca un problema moral desde la perspectiva de un miembro de la sociedad. El individuo se esfuerza por evitar el castigo, se apega a las normas culturales y sociales para ser un buen elemento de la sociedad. Por otro lado, las personas que están en el nivel posconvencional, enfocan los problemas morales desde una perspectiva superior a la sociedad. Es decir, pueden actuar más allá de las normas y leyes dadas por la ciudadanía.

Los autores que se han concebido, o de hecho, han comenzado en una sociedad utópica o revolucionaria han empleado esta perspectiva; como ejemplos de este nivel pueden nombrarse a Martín Luther King, Carlos Marx y Gandhi, o bien individuos que no se enfrentan a dilemas morales y cuyas soluciones propuestas no están definidas por las leyes y normas de una sociedad.

Kohlberg (2008) en sus investigaciones, descubrió que el primer nivel es característico del razonamiento moral en las niñas y los niños más pequeños, pero aún muchos adolescentes y adultos persisten en este razonamiento. El segundo nivel moral surge en la adolescencia, y permanece dominante en el pensamiento moral de la mayoría de los adultos. Es muy raro el tercer nivel, la mayoría de los adultos o los adolescentes no lo adquieren, este razonamiento lo poseen unos cuantos adultos. De acuerdo a Hersh, Reimer y Paolito (2002), Kohlberg señala lo siguiente:

Empezar a hacer paralelismos entre el desarrollo moral y el desarrollo cognitivo. Las personas que adoptan una perspectiva preconvencional son muy concretas en su enfoque. Esto sugiere que su razonamiento moral se base en el nivel preoperatorio o de las operaciones concretas del desarrollo cognitivo. Las personas que adoptan una perspectiva convencional consideran las cuestiones más abstractas de lo que su sociedad esperaría de 
ellos. Están empleando el razonamiento moral que se basa en las primeras operaciones formales. Las personas que adoptan la perspectiva posconvencional, piensan en las categorías puramente formales de lo que sería la mejor solución dados estos principios morales. Emplean un razonamiento basado en operaciones formales avanzadas o consolidadas (Hersh, Reimer y Paolitto, 2002, p. 58).

Mifsud (1983) ha señalado que para entender estos tres niveles del razonamiento moral es preciso comprender la relación entre conocimiento moral y la relación entre conocimientos, efecto y conductas dentro del desarrollo social. Así, este autor indica como para Kohlberg,

... el desarrollo social o del yo, es siempre hacia un equilibrio o una reciprocidad entre las acciones del yo y las acciones de los otros hacia el yo. Este equilibrio en su forma generalizada, es lo que define, la moralidad, concebida como principios de justicia, es decir, de reciprocidad o igualdad (Mifsud, 1983, p. 22).

Piaget y Kohlberg apuntan que puede haber una madurez cognitiva, pero esto no garantiza que será suficiente para una madurez en el juicio moral (Kohlberg, 2008). Por ejemplo, niños y niñas con cociente intelectual por debajo de la media resultaron en los estudios elaborados por Kohlberg por debajo de la media en madurez moral. Sin embargo, en cuanto a empatía o cuestiones donde hay afecto es muy probable que se adapten a la situación moral donde no se perjudique al otro. No obstante, en sus estudios e investigaciones Kohlberg señala que esto depende del nivel cognitivo-evolutivo en el que se encuentre el ser humano.

Para Kohlberg (2008), el aspecto social y la toma de rol dentro de ésta, es parte importante dentro del desarrollo moral del individuo. La estructura de una sociedad es la interacción de muchas estructuras y juicios morales, y sobre todo, tomas de rol. Para esto hay que ubicarse en la posición del otro además de tener muchos aspectos afectivos como la empatía, la culpa, el respeto o el desacuerdo. 
Los estadios que propone Kohlberg implican una estructura común de igualdad y reciprocidad entre los seres con expectativa de uno para con el otro, e indica que,

... la forma más primitiva es la basada en el poder y el castigo, la reciprocidad de obediencia y la libertad de castigo. A continuación (estadio 2) viene el intercambio literal. Luego viene un reconocimiento (estadio 3) de que las relaciones familiares y otras relaciones sociales positivas son sistemas de reciprocidad basada en la gratitud y mantenimiento recíproco de expectativas por parte de los participantes sociales. En el estadio 4 esto evoluciona hasta una idea de orden social en que las expectativas se ganan por el trabajo y la conformidad, y el que uno debe de mantener su palabra y su pacto. En el estadio 5 la noción de orden social flexible o un acuerdo entre individuos libres e iguales, todavía una forma de reciprocidad e igualdad. En el estadio 6 los principios morales se formulan como principios universales de toma de rol recíproco, por ejemplo, la Regla de Oro o la Orden Categórica: Actúa como lo harías después de considerar como todo el mundo debería de actuar si estuviera en esa situación (Kohlberg, 2008, p. 105).

Según Kohlberg el individuo debe tener una toma de rol en la sociedad y se adquiere en la medida que éste participa en un grupo o institución. Se tiene como primer momento en el niño o la niña la teoría de rol en la participación familiar, para lo cual es importante la interacción con los miembros de la familia, en la confianza y a la participación activa en toma de decisiones y con la cesión de responsabilidad del niño y niña hacia la familia. La interacción paterna-materna con el niño o la niña en juegos, discusiones o afecto se verá reflejada en su madurez moral. Sin embargo, difiere de la apreciación de Piaget, en cuanto a la relación entre iguales, es decir, la convivencia entre amigos no hace que su madurez moral avance o lo coloque en otro nivel más avanzado.

Respecto a instituciones secundarias como las leyes, los gobiernos y el trabajo, el individuo con un nivel socioeconómico bajo no se siente responsable de lo que suceda, ni con las ins- 
tituciones de gobierno, ni con la economía, a diferencia de los individuos de clase media o alta. Así, la madurez moral del individuo depende mucho de las interacciones o influencias sociales en las respuestas a estos aprendizajes culturales y procesos cognitivos-estructurales que influyen mutuamente.

Para probar lo que Kohlberg señalaba sobre las interacciones y sus efectos sobre el juicio moral, Linde (2009) menciona que,

... Blatt le propuso a Kohlberg una tesis doctoral sobre educación moral, [...] el método que eligieron fue llevar a cabo sistemáticamente una serie de discusiones sobre dilemas morales hipotéticos en una clase de una escuela dominical judía. La forma de llevar a cabo las discusiones se inspiraba en el método socrático, crear controversias entre los sujetos estimulando el contraste de pareceres sobre las razones que justifican las decisiones de distintos sujetos, acerca de curso de acción más adecuado en cada dilema. [...] después de un semestre de discusiones dominicales, Blatt comparó el nivel alcanzado con el nivel de desarrollo moral inicial de sus sujetos encontrando que entre un cuarto y la mitad de los estudiantes avanzó total o parcialmente un estadio en dicho periodo. El progreso de los alumnos de Blatt demostró que podía estimularse el desarrollo de los alumnos, de las estructuras de razonamiento moral, dando lugar a una investigación intensa sobre intervención educativa (Linde, 2009, p. 11).

Sin embargo, para Kohlberg la estructura esencial de la moralidad es una estructura de justicia: "En definitiva, la parte central de la justicia es la distribución de los derechos y deberes regulados por conceptos de igualdad y reciprocidad" (Kohlberg, 2008 p. 197) Las personas tienen como distinción fundamental de la moral su sentido de justicia. Autores como Kant y Piaget hablan de la importancia de la moral, haciendo hincapié en el concepto de norma y respeto a las normas, esto lleva a entender que las teorías cognitivas-evolutivas tienen supuestos comunes y son: 
1. El desarrollo moral tiene un componente básico cognitivo estructural o moral juicial. 2. La motivación básica para la moralidad es una motivación generalizada por la aceptación, la competencia, la autoestima, o la autocomprensión, más que por el encuentro de las necesidades biológicas con la reducción de la ansiedad y el miedo. 3. Los aspectos más importantes del desarrollo moral son culturalmente universales, porque todas las culturas tienen unos orígenes comunes de interacción social, de toma de rol, y de conflictos social que requieren una integración moral. 4. Las normas y principios morales básicos son estructuras que surgen a través de unas experiencias de interacción social más que a través de la interiorización de las reglas que existen como estructuras externas; los estadios morales no se defienden por reglas interiorizadas, sino por estructuras de interacción entre el yo y otros. 5. Las influencias ambientales dentro del desarrollo moral están defendidas por la calidad y extensión general del estímulo cognitivo y social a través del desarrollo del niño más que por las experiencias específicas con los padres o las experiencias de disciplina y castigo (Kohlberg, 2008, p. 208).

Es importante para el individuo actuar ubicándose en el lugar del otro o de las diversas personas implicadas en un conflicto moral. Esto no es tan sencillo, pero el diálogo hace al ser humano integrarse y poder tomar decisiones con mayor evolución cognitiva, ya sea en la escuela, en la familia o con los amigos y amigas. Esa acción es fundamental en los niños y niñas de edades tempranas, así como en los jóvenes para su desarrollo moral. Kohlberg descubre como en las escuelas se promueve el desarrollo moral individual y la visión de la justicia, pero eligiendo la democracia como medio para el desarrollo moral. La democracia es entendida de la siguiente manera:

Cada grupo social necesita tomar decisiones que vinculan a todos los miembros del mismo con el objeto de velar por la propia supervivencia ya sea interna o externa. Sin embargo, también las decisiones de grupo son tomadas por individuos (el grupo como tal no decide); por lo tanto, para que una decisión tomada por individuos (uno, pocos, muchos, todos) pueda ser aceptada como decisión colectiva, es necesario que se le tome con base en reglas (no importa si escritas o de costumbre (Bobbio, 2009, p. 62). 
Al respecto, Kohlberg, Power y Higgins (2009) señalan:

La primera de las consideraciones prácticas es que, dado que las reuniones democráticas se ocupan de problema y soluciones de la vida real, pueden promover de manera más eficaz el desarrollo moral de las discusiones sobre dilemas hipotéticos. Segundo, la democracia, el equiparar las relaciones de poder, estimula a los estudiantes a pesar por sí mismos y a no depender de autoridades externas para que piensen por ellos. Tercero, si aceptamos el principio de Dewey de aprender haciendo, entonces el mundo más eficaz de enseñar a los estudiantes los valores democráticos de nuestra sociedad es darles la oportunidad de practicarlos. Cuarto, como observó Mill, es más probable que los errores se corrijan en una sociedad democrática, que aliente la libre expresión y el análisis de las opiniones, que en una sociedad cerrada autoritaria. Esto significa que es más probable que directivos y profesores tomen decisiones más prudentes si incluyen a los estudiantes en el proceso. Quinto, la democracia puede ayudar a superar la brecha entre la cultura y de los adultos y al de los pares en la escuela al crear un sentimiento compartido de propiedades de las reglas escolares y de responsabilidad por ellas. Finalmente, la democracia estimula a los estudiantes a seguir las normas de la escuela. Tras votar públicamente las reglas, los individuos experimentan presiones personales y sociales (Kohlberg, Power y Higgins, 2009, p. 42).

En un estudio realizado a nivel nacional entre jóvenes de 12 a 19 años de edad, solo el 54\% indicó como la democracia es preferible a cualquier otra forma de gobierno (Uribe, 2006, p 5). El vínculo entre democracia y moral depende del respeto o como interpretemos ese respeto como principio moral hacia las personas.

En la moral Kantiana el respeto por el ser humano implica un aprecio a su naturaleza libre y racional, lo cual conduce a tratar el tema de la autonomía. Según Piaget (Kohlberg, 2008), para la autonomía del ser humano es necesario la cooperación; en sus estudios descubrió como los infantes al relacionarse con los pares y llegar a acuerdos en el juego, se daban cuenta como las reglas no dependerían de los mayores sino de los acuerdos 
entre ellos y ellas. Al igual que Piaget, en sus señalamientos de la etapa 6, Kohlberg (2008) específica que para llegar a ésta se requiere que los individuos consideren los reclamos de la otra, desde su punto de vista, hasta alcanzar una solución que puedan aceptar ambas partes.

Es importante el respeto por las personas autónomas, lo cual hace que existan formas democráticas de tomar decisiones. Pero la democracia no es darles a los estudiantes el voto, significa mucho más que eso, es un proceso de "comunicación moral" (Kohlberg, 2008, p. 47). Pero, las instituciones educativas apelan a una educación moral; al respecto Cortina (1995) ha señalado que,

... la primera tarea de la educación moral consiste en formar a los niños como hombres e interesarles más tarde en los valores de la ciudadanía. Sin embargo, ambas cosas no pueden hacerse por separado, porque las personas, para devenir tales a través del proceso de socialización, necesitamos unas señas de identidad que brotan de distintas formas de pertenencia a la sociedad y, en este sentido, la ciudadanía ofrece dos ventajas específicas: 1) el ejercicio de la ciudadanía es crucial para el desarrollo de la madurez moral del individuo, porque la participación en la comunidad destruye la inercia, y la consideración del bien común alimenta el altruismo; 2) la ciudadanía subyace a las otras identidades y permite suavizar los conflictos que pueden surgir entre quienes profesan distintas ideologías, porque ayuda a cultivar la virtud política de la conciliación responsable de los intereses en conflicto. Para formar hombres es necesario, pues, formar también ciudadanos (Cortina, 1995, p.51).

A su vez, Diaz-Serrano (2015) declara que,

... en los últimos años, numerosos estudios se han dedicado a la validación o adaptación de pruebas para medir estadios de desarrollo moral, poniendo a prueba en el proceso hipótesis que relacionan el desarrollo moral con aspectos como el desarrollo político y religioso, el desarrollo profesional, los procesos de democratización, ideologías políticas, la comprensión internacional o la trasgresión de los símbolos nacionales (DíazSerrano, 2015, p. 5). 


\section{Metodología}

Con el fin de determinar el nivel moral de los estudiantes de esta investigación se adaptó uno de los dilemas de Kohlberg, y a partir de este se elaboró una encuesta, con ocho (8) preguntas. La investigación es del tipo cualitativa y exploratoria.

La encuesta se aplicó a una muestra de 100 alumnos de 350 integrantes el primer semestre de la Licenciatura en Contaduría de la Unidad Académica de Contaduría y Administración de la Universidad Autónoma de Zacatecas (México). La selección de los 100 estudiantes se hizo al azar. A partir de la encuesta, con el dilema, se contestó en forma individual y con respuestas abiertas. Dicho dilema se describe a continuación:

En Zacatecas hay una mujer que padece un tipo especial de cáncer y va a morir pronto. Hay un medicamento que los médicos piensan que le puede salvar. Es una sustancia que un farmacéutico de la ciudad acaba de descubrir. La droga es cara, pero el farmacéutico está cobrando diez veces lo que le costado a él hacerla. El pagó $\$ 20,000$ (veinte mil pesos por la sustancia y está cobrando $\$ 200,000$ (doscientos mil pesos) por una pequeña dosis del medicamento. El esposo de la mujer enferma, José, acude a todo el mundo que conoce para pedir prestado el dinero, peor sólo puede reunir unos 100.000 (cien mil pesos) que es la mitad de lo que cuentas. Le dice al farmacéutico que su esposa se está muriendo le pide que le venda el medicamento más barato o le deje pagar más tarde. El farmacéutico dice: No, yo lo descubrí y voy a sacar dinero de él. José está desesperado y piensa en atracar el establecimiento para robar la medicina para su mujer.

1. ¿Debe José robar la medicina? ¿Por qué si o por qué no?

2. Si José no quiere a su esposa, ¿debe robar la droga para ella? ¿Por qué sí o por qué no?

3. Suponiendo que la persona que se muere no es mujer, sino un extraño, ¿debe José robar la medicina para un extraño? ¿Por qué si o por qué no?

4. (Si estas a favor de robar el medicamento para un extraño) Suponiendo que se trata de un animal que él quiere, ¿debe robar el medicamento? ¿Por qué sí o por qué no? 
5. De todas formas ¿por qué debe la gente hacer cualquier cosa para salvar la vida de otro?

6. Está contra la ley el que José robe, ¿lo hace esto moralmente malo? ¿Por qué si o por qué no?

7. ¿De todos modos, por qué debe la genta generalmente hacer todo lo que pueda por evitar ir contra la ley?

8. ¿Cómo se relaciona esto con el caso de José?

La primera pregunta está ideada para provocar los primeros pensamientos sobre el conflicto del sujeto. Las siguientes preguntas son las razones del sujeto para escoger un valor sobre el otro, entrar en el proceso de razonamiento de éste es una parte particularmente importante de la entrevista (Kohlberg, 2002, p 53).

A partir de los resultados obtenidos se determinó el nivel y estadio de la moral acorde a la Teoría de Kohlberg.

\section{Resultados}

Como se muestra en la figura 1, el $60 \%$ de los estudiantes entrevistados se encuentran en el Nivel 1 (Preconvencional), donde el juicio moral se basa en los castigos o causas físicas más que en las personas; Estadio 2, donde impera el egoísmo, se satisface lo de uno y ocasionalmente lo del otro y se espera reciprocidad con el otro actor. En sus respuestas sugieren que si no hay otra solución se debe de infringir la ley. También ven la vida de un animal o de una persona con el mismo aprecio. Se habla de la cooperación y la solidaridad y se toman los juicios morales con apego al bienestar común. El otro $40 \%$ de los estudiantes se encuentran en el Nivel 2 (Convencional), donde el valor moral es interpretar roles buenos o correctos, mantener el orden y estar a la altura de las expectativas de los demás, Los Estadios 3 y 4 implican que se preocupan por el deber ser, muestran respeto por la autoridad y mantienen el orden social, pero también están dispuestos a infringir la ley por una acción noble. 


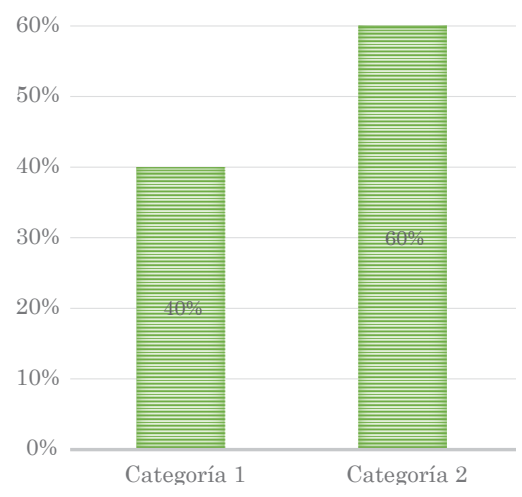

Figura 1. Razonamiento moral de los alumnos entrevistados. Fuente: (Elaboración propia).

Para Kohlberg (2008), estos ejercicios del juicio moral son un proceso cognitivo que permite reflexionar sobre nuestros valores y ordenarlos en una jerarquía lógica. La acción de la moral no se limita a raros momentos en la vida y tieneb como fundamento el pensamiento que empleamos para extraer sentido de los conflictos morales que surgen en la vida diaria.

\section{Análisis de las preguntas}

De las tablas 2 a la 9 se presentan los resultados obtenidos a cada una de las preguntas formuladas en el dilema.

TABla 2

Análisis de las respuestas a la primera pregunta ¿Debe José robar la medicina? ¿Por qué si o por qué no?

\begin{tabular}{cl}
\hline Estudiantes & \multicolumn{1}{c}{ Respuestas } \\
\hline 56 & $\begin{array}{l}\text { No debe de robar la medicina, porque no se va a } \\
\text { curar, ira a la cárcel si lo hace, no es la mejor opción. }\end{array}$ \\
35 & $\begin{array}{l}\text { Sí, robar la medicina, pero no toda, debe de robarla } \\
\text { para salvar a su esposa. }\end{array}$ \\
9 & Se debe de tener valores \\
\hline
\end{tabular}

Fuente: Elaboración propia. 
TABLA 3

Análisis de las respuestas a la segunda pregunta.

Si José no quiere a su esposa, ¿debe robar la droga para ella? ¿Por qué sí o por qué no?

\begin{tabular}{cl}
\hline Estudiantes & \multicolumn{1}{c}{ Respuestas } \\
\hline 49 & $\begin{array}{l}\text { No debe de robar la medicina, porque no la } \\
\text { quiere. }\end{array}$ \\
44 & $\begin{array}{l}\text { Si debe de robar la medicina, no importa que no } \\
\text { la quiera, es un ser humano }\end{array}$ \\
7 & Indecisos \\
\hline
\end{tabular}

Fuente: Elaboración propia.

TABLA 4

Análisis de las respuestas a la tercera pregunta.

Suponiendo que la persona que se muere no es mujer, sino un extraño,

¿debe José robar la medicina para un extraño?

¿Por qué si o por qué no?

\begin{tabular}{cl}
\hline Estudiantes & \multicolumn{1}{c}{ Respuesta } \\
\hline \multirow{2}{*}{70} & $\begin{array}{l}\text { No debe de robar la medicina porque no es } \\
\text { lo correcto, no conoce a la persona, no es su } \\
\text { esposa, puede ser una mala persona, le traerá } \\
\text { consecuencias legales. }\end{array}$ \\
& $\begin{array}{l}\text { Sí debe de robar la medicina si se pone en el } \\
\text { lugar de la persona. }\end{array}$ \\
& $\begin{array}{l}\text { Sí debe de robar la medicina por ayudar a un } \\
\text { ser humano. }\end{array}$ \\
& $\begin{array}{l}\text { No debe de robar la medicina, porque lo meterán } \\
\text { a la cárcel, pero también debe de pensar que } \\
\text { salvaría un ser humano. }\end{array}$ \\
\hline
\end{tabular}

Fuente: Elaboración propia. 
TABLA 5

Análisis de las respuestas a la cuarta pregunta.

(Si estas a favor de robar el medicamento para un extraño)

Suponiendo que se trata de un animal que él quiere, ¿debe robar el medicamento?

¿Por qué sí o por qué no?

\begin{tabular}{cl}
\hline Estudiantes & \multicolumn{1}{c}{ Respuestas } \\
\hline 63 & $\begin{array}{l}\text { No debe de robar el medicamento, no es lo } \\
\text { correcto, tendría problemas legales. }\end{array}$ \\
13 & $\begin{array}{l}\text { No contestaron } \\
\text { Sí debe de robar porque es un ser querido } \\
\text { no importa si es un animal. } \\
\text { Es un ser vivo y se debe de ayudar. } \\
\text { No es más importante el ser humano que } \\
\text { un animal. }\end{array}$ \\
\hline
\end{tabular}

Fuente: Elaboración propia.

TABla 6

Análisis de las respuestas a la quinta pregunta.

De todas formas,

¿por qué debe la gente hacer cualquier cosa para salvar la vida de otro?

\begin{tabular}{cl}
\hline Estudiantes & \multicolumn{1}{c}{ Respuestas } \\
\hline 76 & $\begin{array}{l}\text { Porque algún día puede estar en su lugar. } \\
\text { La vida es valiosa. } \\
\text { Por amor a la otra persona. }\end{array}$ \\
21 & Solo si es alguien de la familia. \\
2 & No contestaron \\
1 & Indeciso \\
\hline
\end{tabular}

Fuente: Elaboración propia. 
TABLA 7

Análisis de las respuestas de la sexta pregunta.

Está contra la ley el que José robe, ¿lo hace esto moralmente malo?

¿Por qué si o por qué no?

\begin{tabular}{|c|c|}
\hline Estudiantes & Respuestas \\
\hline 53 & $\begin{array}{l}\text { No debe de robar, porque tendrá problemas } \\
\text { legales, irá a la cárcel, tiene que tener } \\
\text { valores. }\end{array}$ \\
\hline 20 & Indecisos \\
\hline 22 & $\begin{array}{l}\text { Debe de robar José porque no tiene otra } \\
\text { alternativa, no es malo por eso, no importa } \\
\text { que lo metan a la cárcel y salva a su esposa. } \\
\text { A veces se tiene que ir en contra de la ley. }\end{array}$ \\
\hline 20 & Indecisos. \\
\hline 1 & No contestó. \\
\hline
\end{tabular}

Fuente: Elaboración propia.

\section{TABLA 8}

Análisis de las respuestas de la séptima pregunta.

¿De todos modos, por qué debe la genta generalmente

hacer todo lo que pueda por evitar ir contra la ley?

\begin{tabular}{cl}
\hline Estudiantes & \multicolumn{1}{c}{ Respuestas } \\
\hline 57 & Evitar problemas con la ley \\
30 & Llevar una vida tranquila \\
4 & No contestaron \\
4 & Indecisos \\
5 & A veces se debe de ir en contra de la ley \\
\hline
\end{tabular}

Fuente: Elaboración propia. 
TABLA 9

Análisis de las respuestas de la octava pregunta. ¿Cómo se relaciona esto con el caso de José?

\begin{tabular}{cl}
\hline Estudiantes & \multicolumn{1}{c}{ Respuesta } \\
\hline 13 & No contestaron \\
11 & $\begin{array}{l}\text { Porque José puede infringir la ley } \\
\text { Encuentra relación con José, por el robo y } \\
\text { no debe de hacerlo. } \\
\text { No debe de infringir la ley- } \\
58\end{array}$ \\
\hline
\end{tabular}

Fuente: Elaboración propia.

En cada una de las respuestas, los alumnos están más interesados en respetar las leyes civiles, que en ayudar a un ser humano o bien a alguien que lo necesita. ¿Cómo debe de intervenir el sector educativo para poder revertir esta actitud donde el otro no importa, donde mi estado de bienestar es lo importante y mi entorno no es de mi interés? Un aspecto importante en la formación educativa es realizar estrategias para fomentar la colectividad cívica, la justicia, los valores éticos y morales en los estudiantes.

\section{Conclusiones}

Para la Universidad Autónoma de Zacatecas-UAZ (México) su principal objetivo es rediseñar las actividades académicas y la estructuración curricular de sus unidades y programas, comprometiéndose a generar egresados con habilidades y destreza para la vida social académica, creativas, volitivas, relacionales, heurísticas e instrumentales que les permita acceder desde una perspectiva transdisciplinaria y propositiva. Siguiendo las tareas que la UAZ tiene hacia los alumnos se concluye de acuerdo a los resultados de la investigación en 
cuanto a la moral de los estudiantes de primer semestre, lo siguiente:

Es de vital importancia que las clases impartidas por los diferentes maestros tengan aborden de manera trasversal los temas de ética, valores morales, ciudadanía, justicia y democracia con el fin de desarrollar en los alumnos(as) una evolución en su madurez moral. Además, los esfuerzos deben ser de manera bilateral, es decir la educación es compartida entre familia y escuela, con el fin de lograr un intercambio de información que favorezca la construcción de una verdadera institución educativa, proponiendo conferencias y actividades donde los padres y madres de familia se involucren.

Se debe fomentar las actividades colectivas para inculcar principios de la existencia social, colaboración, respeto, justicia, dialogo y democracia, entre otras. Actividades donde los estudiantes,se sientan miembros de una colectividad, pero también de una comunidad política, forjando un vínculo de vital importancia para llegar a una democracia comunicativa, donde lo importante es la interacción entre las personas. Para esto se propone la formación de un club de la Unidad Académica (FCA CLUB).

Utilizar la tecnología como un medio didáctico para que los estudiantes expresen su creatividad, lingüística pictórica, musical, gráfica y así compartan sus experiencias.

Este compromiso educativo debe ser a mediano y largo plazo, es decir, el docente interesado en este tema ético de valores democracia y justicia deberá hacer un compromiso donde se acuerde inculcar todos estos aspectos es un aprendizaje continuo.

\section{Referencias}

Barra, E. (1987). El desarrollo moral: una introducción a la teoría de Kohlber. Revista Latinoamericana de Psicología, 19(1). 7-18. Recuperado de http://www.redalyc.org/ html/805/80519101/ 
Bell, D. (2006). Las contradicciones culturales del capitalismo. Madrid: Alianza.

Bobbio, N. (2009). El futuro de la Democracia. Estudios Políticos, 46(1). 62-73. Recuperado de http://dx.doi.org/10.22201/ fcpys.24484903e.1985.1.60131

Cortina, A. (1995). La educación del hombre y del ciudadano. Revista Iberoamericana de Educación, 7(1), 41-63. Recuperado de https://rieoei.org/RIE/article/view/1199

Cortina, A. (2003). Conferencia: Ética, ciudadanía y modernidad. Revista Cyber Humanitas, 27(1). 1-13. Recuperado de https://web.uchile.cl/vignette/cyberhumanitatis/CDA/vida_ sub_simple3/0,1250,PRID\%253D7562\%2526SCID\%253D 7566\%2526ISID\%253D347,00.html

Craig G. y Baucum D. (2009). Desarrollo psicológico. (9 ed.). México, D.F.: Pearson.

Díaz-Serrano, J. (2015). El desarrollo del juicio moral en Kohlberg como factor condicionante del rendimiento académico en ciencias sociales de un grupo de estudiantes de educación secundaria. Revista Electrónica EDUCARE, 19(3), 1-14. Recuperado de https://dialnet.unirioja.es/servlet/articulo?codigo $=5169749$

Hersh R., Reimer J. y Paolitto D. (2002). El crecimiento moral: de Piaget a Kohlberg. Madrid: Narcea Ediciones.

Kant, I. (2003). Crítica de la Razón práctica. Buenos Aires: La Página. Recuperado de http://www.manuelosses.cl/ VU/kant\%20Immanuel_Critica\%20de\%20la\%20razon\%20 practica.pdf

Kant, I. (1788/1961). Crítica de la Razón Práctica. Buenos Aires: Losada.

Kohlberg L. (2008). Psicología del desarrollo moral. (2 ed.). Bilbao: Desclée.

Kohlberg, L., Power, F. y Higgins A. (2009). La educación moral según Lawrence Kohlberg. Barcelona: Gedisa. 
Linde, A. (2009). La educación moral según Lawrence Kohlberg: Una Utopía realizable. Praxis Filosófica, 28(1). 7-22. Recuperado de https://www.redalyc.org/ht$\mathrm{ml} / 2090 / 209014646001 /$

Mac Pherson, C. B. (2005). La democracia liberal y su época. Madrid: Alianza. Recuperado de https://perio.unlp.edu. ar/catedras/system/files/macpherson.pdf

Mifsud, T. (1983). Los seis estadios del juicio moral con aplicación pedagógica. [Documento de Trabajo 3.428 del Centro de Investigación y Desarrollo de la Educación - CIDE]. Santiago de Chile: Universidad Católica de Chile. Recuperado de http://repositorio.uahurtado.cl/bitstream/handle/11242/8692/3428.pdf

Palomo, A. (1989). Laurence Kohlberg: Teoría y práctica del desarrollo moral en la escuela. Revista interuniversitaria de formación del profesorado, 4(1). 79-90. Recuperado de https://dialnet.unirioja.es/servlet/articulo?codigo=117615

Platón. (1981). Diálogos Socráticos. (16 ${ }^{\text {ta }}$ ed.) México, D.F.: Cumbre.

Sánchez A. (2000). Formación de valores: Teoría, reflexión y respuesta. México, D.F.: Editorial Grijalbo.

Uribe, C. (2006). Un Sexenio de Oportunidad Educativa México 2007-2012. Banco Interamericano de Desarrollo. Departamento Regional de Operaciones II. [Nota política]. Recuperado de http://investigadores.cide.edu/aparicio/ BID_NotaPolitica_Educacion_06.pdf

Valcárcel, A. (1988). Hegel y la ética: sobre la superación de la "mera moral". Barcelona: Anthropos.

Zerpa, C. (2007). Tres teorías del desarrollo del juicio moral: Kohlberg, Rest, Lind. Implicaciones para la formación moral. Laurus, 13(3). 137-157. Recuperado de https:// www.redalyc.org/html/761/76102308/ 
María Glafira Sandoval Benavides es Doctora en Ciencia Política con Maestría en Educación y Licenciada en Educación. Perteneciente al cuerpo académico: Gestión, Evaluación y Procesos de Capacitación de las Políticas Públicas en México en la Línea de investigación: Políticas Públicas de la Unidad Académica de Contabilidad y Administración de la Universidad Autónoma de Zacatecas (Zacatecas, México). https://orcid.org/0000-00022376-7998

María Teresa Villegas Santillán es Doctora en Administración con Maestría en Administración Pública y Licenciada en Contaduría. Perteneciente al Cuerpo Académico: Gestión, Evaluación y Procesos de Capacitación de las Políticas Públicas de México en la Línea de investigación: Políticas Públicas de la Unidad Académica de Contaduría y Administración de la Universidad Autónoma de Zacatecas (Zacatecas, México). https:// orcid.org/0000-0002-6985-5256

Reina Margarita Vega Esparza es Doctora en Metodología de la Investigación con Maestría en Administración y Licenciatura en Contaduría. Perteneciente al cuerpo académico en Gestión, Evaluación y Procesos de Capacitación de las Políticas Públicas de México en la línea de investigación: Políticas Públicas de la Unidad Académica de Contaduría y Administración de la Universidad Autónoma de Zacatecas (Zacatecas, México). https:// orcid.org/0000-0001-5151-5977 